\title{
Electrical Behavior of Aluminum Nitride Ceramics Sintered with Yttrium Oxide and Titanium Oxide
}

\author{
Jin-Wook Lee, Won-Jin Lee, and Sung-Min Lee ${ }^{\dagger}$ \\ Engineering Ceramic Center, Korea Institute of Ceramic Engineering and Technology, Icheon 17303, Korea \\ (Received September 20, 2016; Revised October 25, 2016; Accepted October 25, 2016)
}

\begin{abstract}
Electrical behavior of AlN ceramics sintered with $\mathrm{Y}_{2} \mathrm{O}_{3}$ as a sintering aid has been investigated with respect to additional TiO dopant. From the impedance spectroscopy, it was found that the grain and grain boundary conductivities have greatly decreased with addition of $\mathrm{TiO}_{2}$ dopant. The $\mathrm{TiO}_{2}$ dopant also increased the activation energy of the grain conductivity by about $0.37 \mathrm{eV}$; this increase was attributed to the formation of an associate between $\mathrm{Al}$ vacancies and $\mathrm{Ti}$ ions at the $\mathrm{Al}$ sites. Similarly, the electronic conductivity was reduced by $\mathrm{TiO}_{2}$ addition. However, $\mathrm{TiO}_{2}$ solubility in $\mathrm{AlN}$ grains was below the detection limit of typical EDX analysis. Grain boundary was clean, without liquid films, but did show yttrium segregation. The transference number of ions was close to 1 , showing that AlN is a predominantly ionic conductor. Based on the observed results, the implications of using AlN applications as insulators have been discussed.
\end{abstract}

Key words : AlN, Electrical behavior, $\mathrm{Y}_{2} \mathrm{O}_{3}, \mathrm{TiO}_{2}$

\section{Introduction}

A luminum nitride (AlN), whose theoretical thermal conductivity is $320 \mathrm{~W} / \mathrm{mK}$, is being used for electrostatic chucks and heaters in the semiconductor industry. In such applications, in addition to the need for a high thermal conductivity, the electrical conductivity of the ceramics must be well-optimized because their working mechanism depends on an electrical current under a high electrical field. ${ }^{1-6)}$

The oxygen content of approximately $0.8 \mathrm{wt} \%$ inherent to commercial AlN powder is mostly removed from the AlN grains through the forming of grain boundary precipitates with sintering additives such as $\mathrm{Y}_{2} \mathrm{O}_{3}$ and $\mathrm{CaO}$.,5,7) As described by Slack et al., ${ }^{8}$ the remaining oxygen incorporates into the AlN grains by the following reaction

$$
\mathrm{Al}_{2} \mathrm{O}_{3} \stackrel{\mathrm{AIN}}{\longrightarrow} 2 \mathrm{Al}_{\mathrm{Al}}^{\mathrm{x}}+3 \mathrm{O}_{\mathrm{N}}^{\bullet}+V_{A l}^{\prime \prime \prime}
$$

The oxygen defects, substituting for nitrogen ion sites, and the aluminum vacancies were believed to control the electrical and thermal conductivity ${ }^{9-11)}$ It was proposed that the aluminum vacancies are the charge carriers for AlN ceramics. ${ }^{9-11)}$ This conclusion came from complex impedance spectrum studies with respect to temperature. Those studies, however, did not consider the effects of minor impurities such as transition metal oxides. Recently, $\mathrm{TiO}_{2}$ was reported

${ }^{\dagger}$ Corresponding author : Sung-Min Lee

E-mail : smlee@kicet.re.kr

Tel : +82-31-645-1441 Fax : +82-31-645-1492 to have a very strong effect on the electrical properties of AlN ceramics; ${ }^{12,13)}$ the mechanism for this, however, has not been explained yet.

In this study, the electrical conductivities and impedance spectrums of $1 \mathrm{wt} \% \mathrm{Y}_{2} \mathrm{O}_{3}$ - doped AlN ceramics have been measured with respect to the additional $\mathrm{TiO}_{2}$ dopant. Microstructures of the sintered specimens were characterized through high-resolution transmission electron microscopy (HRTEM), and elemental analysis of the grain boundaries were conducted using scanning transmission electron microscopy (STEM). Based on the observed results, the implications of using $\mathrm{AlN}$ as an insulator have been discussed.

\section{Experimental Procedure}

Commercial AlN powder (F-grade, Tokuyama Soda, Japan) was used. According to the manufacturer's data, the powder's major impurity is $0.8 \mathrm{wt} \%$ oxygen, while other metallic impurities were present at levels of less than $10 \mathrm{ppm}$. As a sintering aid, 1 wt\% of $\mathrm{Y}_{2} \mathrm{O}_{3}$ (grade C, H.C. Starck, Germany) was mixed with the $\mathrm{AlN}$ powder. $\mathrm{TiO}_{2}$ dopant $(99.9 \%$, Showa, Japan), at levels ranging from $0.05 \mathrm{wt} \%$ to $1.0 \mathrm{wt} \%$, was also added to the AlN powder. The proportioned mixtures were ball-milled with an anhydrous ethyl alcohol medium in Teflon jars for $20 \mathrm{~h}$. The resultant slurry was dried in an oven at $90^{\circ} \mathrm{C}$ for $24 \mathrm{~h}$ and then hot pressed in a graphite furnace at $1700^{\circ} \mathrm{C}$ for $3 \mathrm{~h}$ under applied pressure of $15 \mathrm{MPa}$.

Insulating properties were measured using the guarded electrode method based on ASTM D257 ${ }^{14)}$ under an electrical field of $500 \mathrm{~V} / \mathrm{mm}$ and after a charging time of $60 \mathrm{sec}-$ 
onds. Complex impedance spectrums were obtained between $150^{\circ} \mathrm{C}$ and $350^{\circ} \mathrm{C}$ using an impedance analyzer (1260, Solartron, UK) and a dielectric interface (1296, Solartron, UK) at a voltage of $1 \mathrm{~V}$. Electronic conductivity was measured at a constant voltage of $1 \mathrm{~V} / \mathrm{mm}$ using a source meter (617, Keithley, USA). Measured impedance spectrum was fitted using the software Zview (ver. 3.1, Scribner Asso., USA). Before the experiments, a silver paste was applied as an electrode and the specimens were annealed at $850^{\circ} \mathrm{C}$ for 20 min in nitrogen atmosphere. Microstructural characterization and elemental analysis were conducted using HRTEM (JEM-4010, Jeol, Japan) and STEM (JEM-2100F, Jeol, Japan). For the TEM analysis, the specimen was thinned and ion-milled following the conventional techniques of sample preparation.

\section{Results}

Figure 1 shows the electrical resistivity measured with respect to the added amounts of $\mathrm{TiO}_{2}$ after a charging time of 60 seconds in an electric field of $500 \mathrm{~V} / \mathrm{mm}$. Even with a $0.05 \mathrm{wt} \%$ addition of $\mathrm{TiO}_{2}$, the resistivity increased more than 1000 times. This high resistivity was maintained with further addition of $\mathrm{TiO}_{2}$. To understand this behavior, impedance was measured with respect to frequency. Fig. 2 shows a typical example of impedance spectra for AlN specimens with $1 \mathrm{wt} \% \mathrm{Y}_{2} \mathrm{O}_{3}$ sintering aid and with an additional $0.05 \mathrm{wt} \%$ of $\mathrm{TiO}_{2}$ as a dopant. Impedance spectra consisted of three semicircles, as was found in the literature: ${ }^{10,11)}$ a semicircle due to grains at high frequency, a semicircle due to grain boundaries at low frequency, and a big semicircle from electrodes at the lowest bound of frequency. In the $\mathrm{AlN}$ specimen without $\mathrm{TiO}_{2}$ dopant, the resistance of the grain is much lower than that of the grain boundary. But, with $\mathrm{TiO}_{2}$ dopant at a level of $0.05 \mathrm{wt} \%$, the grain resistance increased about 2500 times, while the

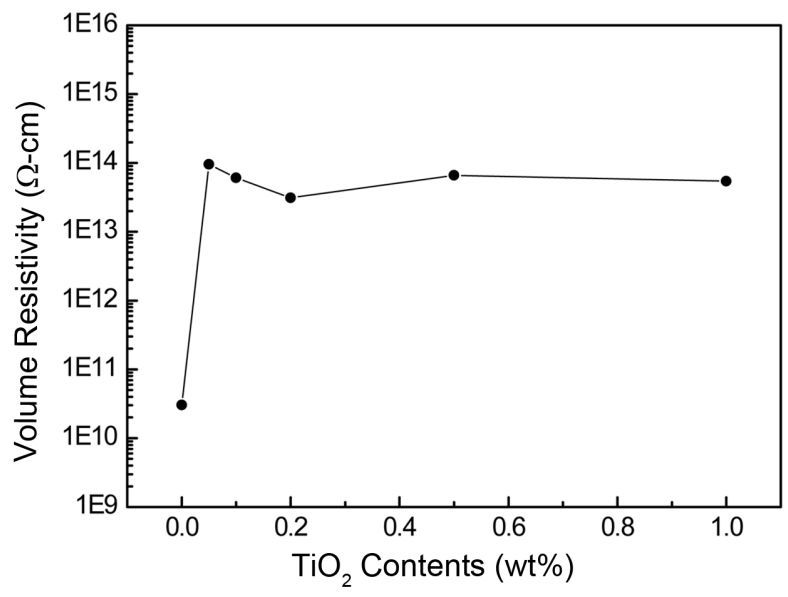

Fig. 1. Volume resistivity of AlN ceramics sintered with $1 \mathrm{wt} \%$ of $\mathrm{Y}_{2} \mathrm{O}_{3}$ with respect to additional amount of $\mathrm{TiO}_{2}$ dopant measured at $500 \mathrm{~V} / \mathrm{mm}$ after charging time of 60 seconds at room temperature. grain boundary resistance increased about 380 times. The grain conductivity of AlN ceramics is known to be mostly ionic, with $\mathrm{Al}$ vacancy as a charge carrier. ${ }^{9-11)}$ Thus $\mathrm{TiO}_{2}$ addition must affect the migration of $\mathrm{Al}$ vacancies.

Figure 3 shows the conductivity changes of the grains and grain boundaries at various temperatures for the above two specimens. Over the investigated temperature range, the specimen with $\mathrm{TiO}_{2}$ dopant showed much lower conductivity than that without dopant. In the specimen without $\mathrm{TiO}_{2}$ dopant, the activation energy of the grain and the grain boundary were very similar, at 0.63 and $0.65 \mathrm{eV}$, respectively. However, in the specimen with $\mathrm{TiO}_{2}$ dopant at a level of $0.05 \mathrm{wt} \%$, the activation energies increased to 1.0 and $0.96 \mathrm{eV}$ for the grain and grain boundary, respectively. Thus, $\mathrm{TiO}_{2}$ addition induced not only a reduction in conductivity but also an increase in the activation energy.

Figure 4 shows the electronic conductivity measured at 1 $\mathrm{V} / \mathrm{mm}$ after a prolonged holding time. Because we used silver as the electrode material and because the measurement temperature was low, the ionic current must be blocked at the electrodes due to limited interface reaction, and thus
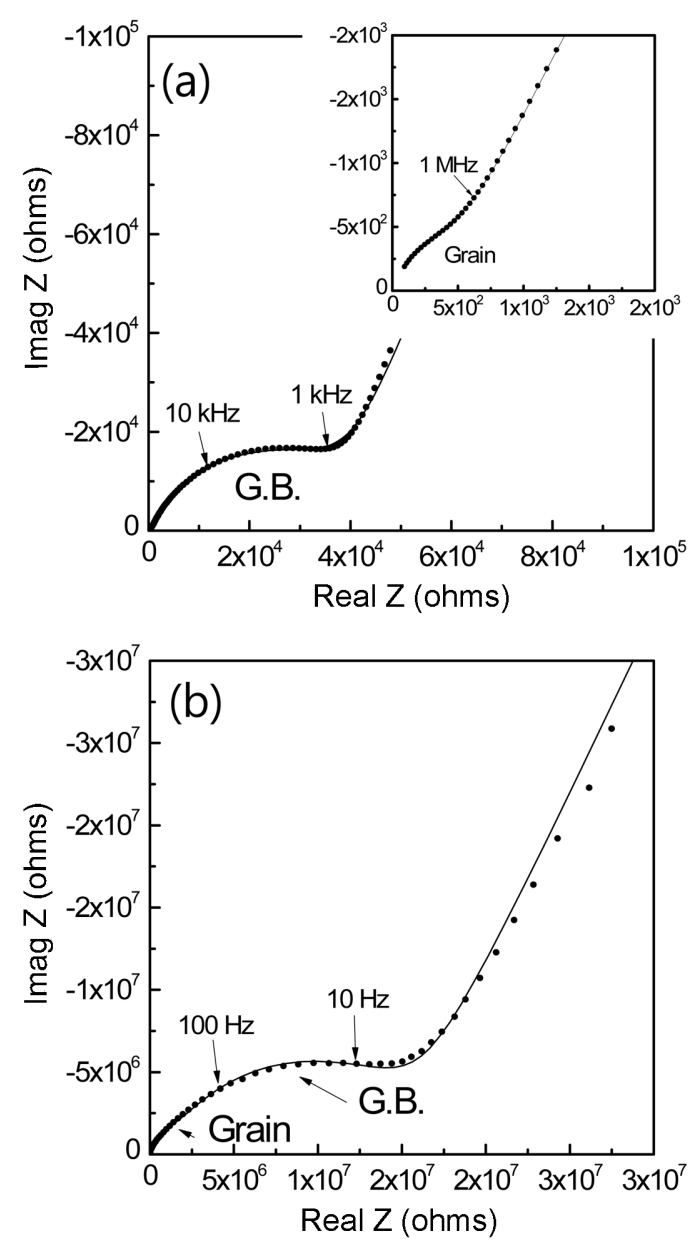

Fig. 2. Complex impedance spectrum of AlN ceramics sintered (a) with1 wt\% of $\mathrm{Y}_{2} \mathrm{O}_{3}$ and (b) with additional amount of $\mathrm{TiO}_{2}$ dopant of $0.05 \mathrm{wt} \%$, measured at $200^{\circ} \mathrm{C}$. 


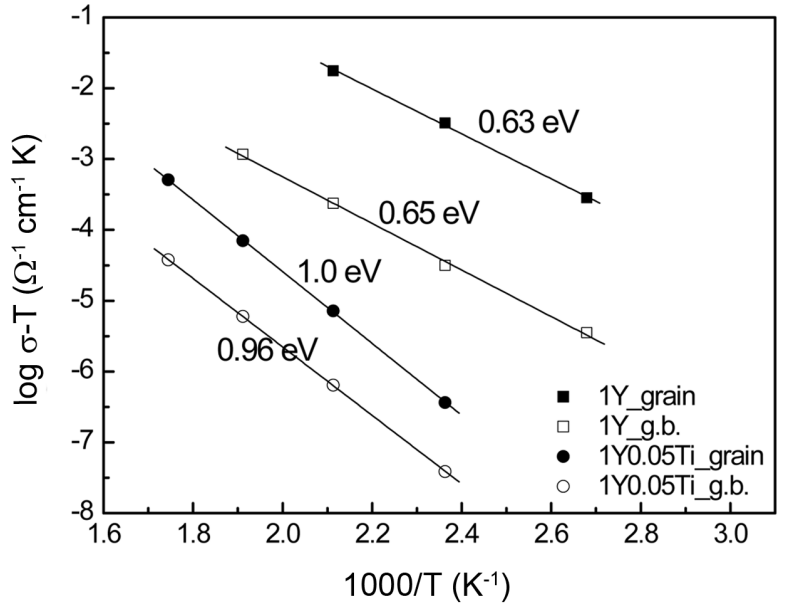

Fig. 3. Grain and grain boundary conductivity with respect to measurement temperature for the specimens sintered with 1 wt\% of $\mathrm{Y}_{2} \mathrm{O}_{3}$ and with additional amount of $\mathrm{TiO}_{2}$ dopant of 0.05 wt\%.

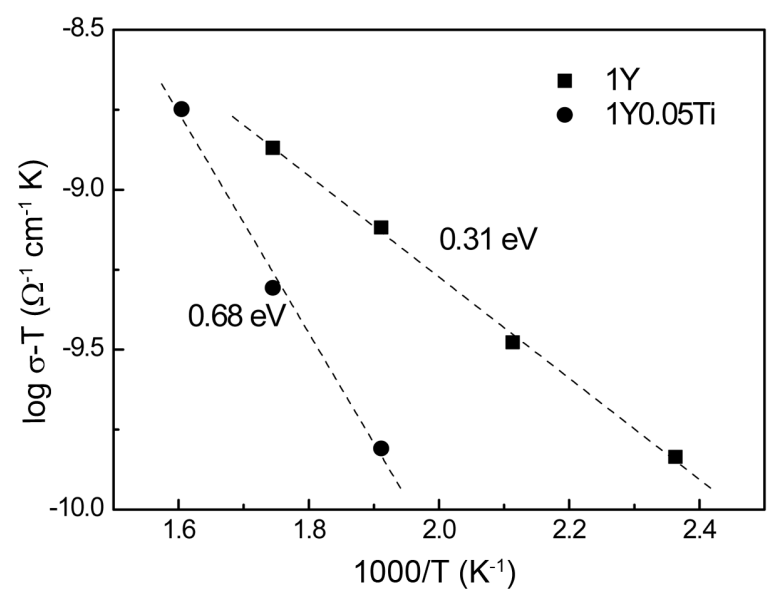

Fig. 4. Electronic conductivity with respect to measurement temperature for the specimens sintered with 1 wt\% of $\mathrm{Y}_{2} \mathrm{O}_{3}$ and with additional amount of $\mathrm{TiO}_{2}$ dopant of $0.05 \mathrm{wt} \%$.

only electronic current is allowed. Therefore, after prolonged application of DC voltage, a steady-state in electronic conduction would be reached, while ionic conduction would be totally blocked. In fact, we conducted very long experiments, for at least 2000 seconds, and then applied a longterm approximation to obtain the steady-state the electronic current. As the ionic conduction, electronic conduction also decreased with the addition of $\mathrm{TiO}_{2}$. The magnitude of the difference between these two samples was not as large as that in the case of ionic conduction. However, the activation energy change showed similar behavior; $\mathrm{TiO}_{2}$ addition increased the activation energy of electronic conduction by $0.37 \mathrm{eV}$.

From the measured values of ionic and electronic conductivity, we were able to obtain the electronic transference number, which is the ratio of electronic to total conductivity (Fig. 5). Because ionic conductivity is much higher than

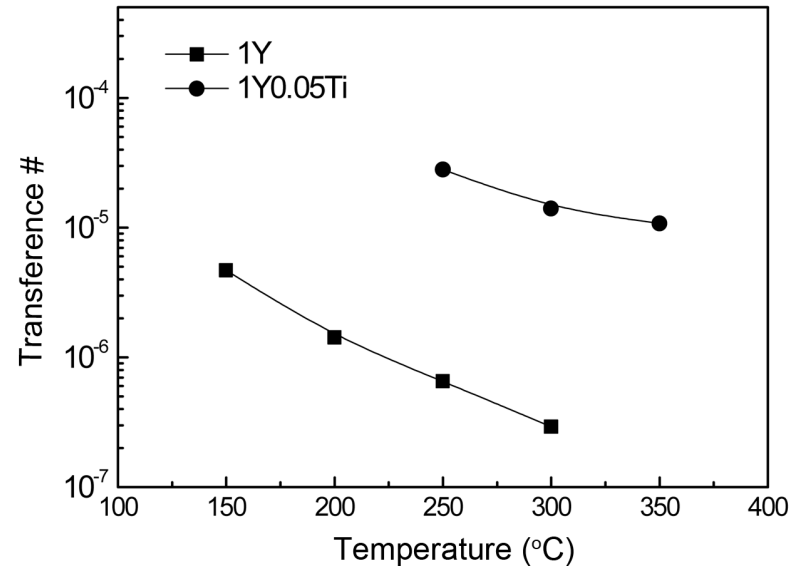

Fig. 5. Electronic transference number with respect to measurement temperature for the specimens sintered with1 wt\% of $\mathrm{Y}_{2} \mathrm{O}_{3}$ and with additional amount of $\mathrm{TiO}_{2}$ dopant of $0.05 \mathrm{wt} \%$.

electronic conductivity, we assumed that the sum of the grain and grain resistances were the total resistance, from which the total conductivity could be obtained. For both specimens, the electronic transference numbers were very small, in the range of $10^{-4}$ to $10^{-7}$, indicating that AlN ceramics are a predominantly ionic conductor at the measurement temperature range. With the addition of $\mathrm{TiO}_{2}$ dopant, the electronic transference number is higher because the reduction of ionic conductivity was much greater than the reduction of electronic conductivity, as shown in Figs. 3 and 4. The number decreased further with increasing measurement temperature because the activation energy of ionic conduction was higher than that of electronic conduction.

To understand this behavior, we observed the microstructure through TEM. For the specimen with $1 \mathrm{wt} \% \mathrm{TiO}_{2}$ dopant, we found very small particles related to $\mathrm{TiO}_{2}$ addition inside the grain and along the grain boundary, as shown in Fig. 6. From the EDX analysis, it can be seen that this material has a composition close to $\mathrm{Ti}_{0.95} \mathrm{Al}_{0.5} \mathrm{~N}$, which means that the added $\mathrm{TiO}_{2}$ reacted with AlN to form nitride particles. However, inside the AlN grains, we found that Ti concentration was below the detection limit of EDX, indicating that Ti has very low solubility in AlN. TiN is known as a conducting material. However, in this case, the particles that were formed inside the grain and along grain boundary were not connected to each other, and thus they did not make a conduction path along the $\mathrm{Ti}_{0.95} \mathrm{Al}_{0.5} \mathrm{~N}$ particles. The formation of $\mathrm{Ti}_{0.95} \mathrm{Al}_{0.5} \mathrm{~N}$ particles from $\mathrm{TiO}_{2}$ also seems to contribute to an increase in oxygen content in the AlN grains. This additional oxygen from $\mathrm{TiO}_{2}$ resulted in a decrease in the thermal conductivity of the specimens from $92.5 \mathrm{~W} / \mathrm{mK}$ without $\mathrm{TiO}_{2}$ addition to $77.6 \mathrm{~W} / \mathrm{mK}$ with addition of $1 \mathrm{wt} \% \mathrm{TiO}_{2}$.

In order to check the atomic scale segregation along the grain boundary, we observed the grain boundary at high magnification and performed EDX analysis across the grain boundary (Fig. 7). As was found in the literature, ${ }^{11)}$ we 

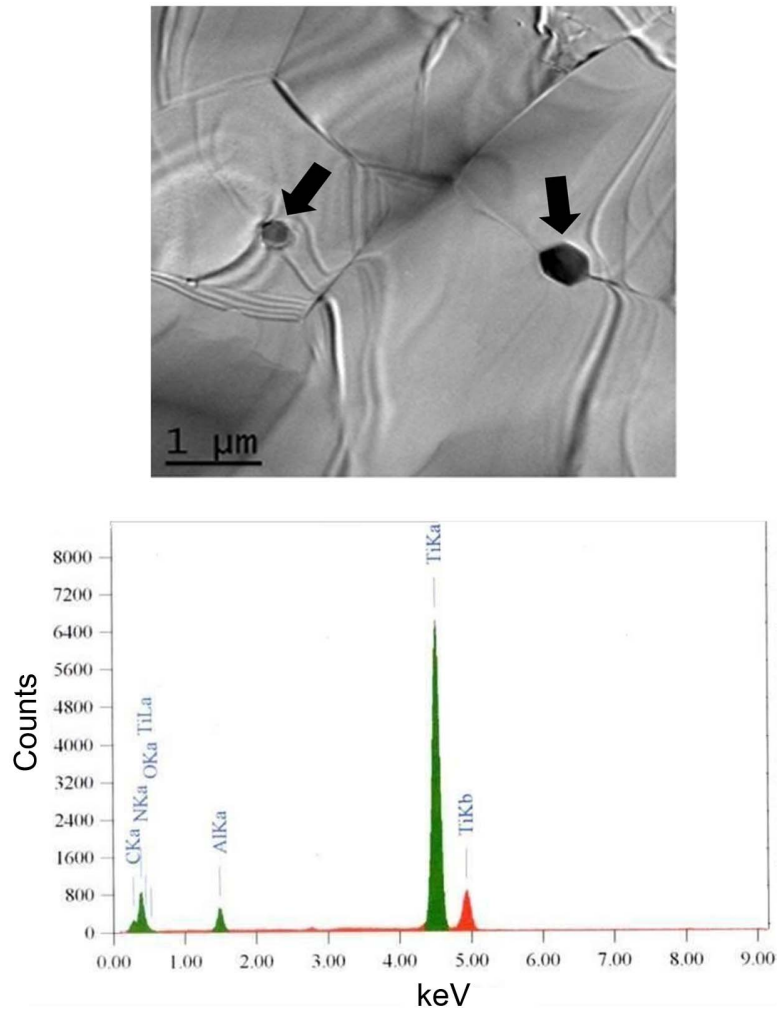

Fig. 6. TEM micrograph analysis of the specimens sintered with $1 \mathrm{wt} \% \mathrm{Y}_{2} \mathrm{O}_{3}$ and 1 wt\% $\mathrm{TiO}_{2}$ showing $\mathrm{Ti}_{0.95} \mathrm{Al}_{0.5} \mathrm{~N}$ particles and their EDX analysis.

found Y segregation along the grain boundary, but there was no evidence of Ti segregation. The fact that the grain boundary conductivity was much lower than the grain conductivity might be attributed to this $\mathrm{Y}$ segregation. The result, that $\mathrm{Y}$ segregation in $\mathrm{Al}_{2} \mathrm{O}_{3}$ was determined to form more ionic bonds, may be related to this phenomenon. ${ }^{15)}$

From the above TEM analysis, we suggest that most of the Ti resulting from added $\mathrm{TiO}_{2}$ remains as $\mathrm{Ti}_{0.95} \mathrm{Al}_{0.5} \mathrm{~N}$ particles along the grain boundary; only a very small fraction was incorporated into the AlN grains. This is consistent with the calculated phase diagram for cubic TiN and AlN. ${ }^{16)}$ Though cubic AlN was considered instead of Wurtzite AlN, the solubility of TiN in AlN was very low. ${ }^{16)}$ However, that low solubility was sufficient to have an impact on the ionic and electronic conductions, as shown above.

\section{Discussion}

In order to understand effects of $\mathrm{TiO}_{2}$ addition on the electrical properties of AlN ceramics, we have to first understand how Ti ions are located inside the AlN lattice. Using TEM analysis, we found a very small solubility of Ti in AlN grains. When we consider the ionic sizes of $\mathrm{Ti}$ and $\mathrm{Al}$ ions $\left(0.61 \AA\right.$ for $\mathrm{Ti}^{4+}, 0.67 \AA$ for $\mathrm{Ti}^{3+}$, and $0.54 \AA$ for $\left.\mathrm{Al}^{3+}\right),{ }^{17)}$ the size difference between the $\mathrm{Ti}$ and $\mathrm{Al}$ ions is relatively large: $13 \%$ in $\mathrm{Ti}^{4+}$ and $24 \%$ in $\mathrm{Ti}^{3+}$. Thus $\mathrm{Ti}$ ions inside the AlN lattice will probably prefer a +4 valence instead of a +3
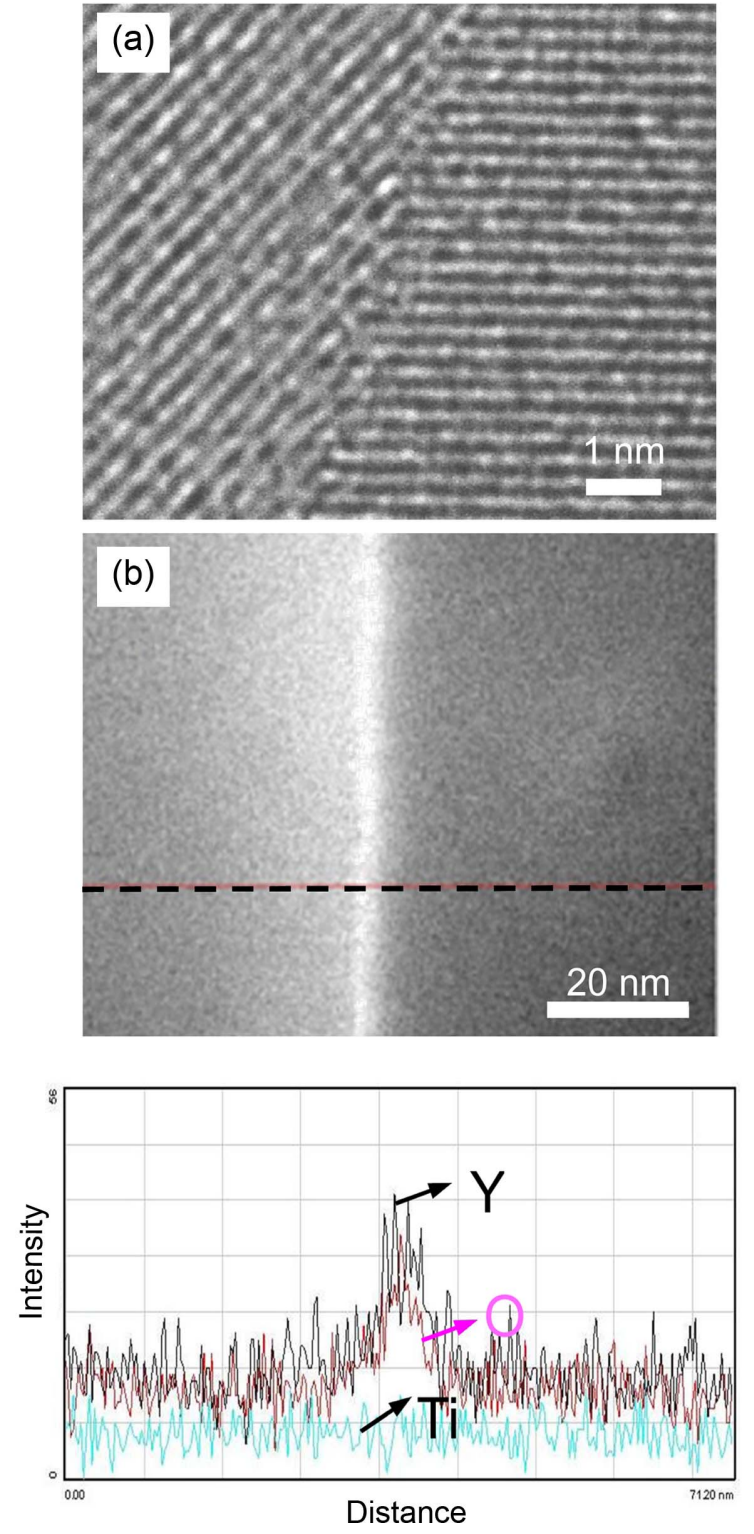

Fig. 7. TEM micrograph and EDX analysis of the specimens sintered with 1 wt $\% \mathrm{Y}_{2} \mathrm{O}_{3}$ and 1 wt $\% \mathrm{TiO}_{2}$ : (a) high resolution image showing grain boundary and (b) STEM image with EDX analysis across the grain boundary.

valence, resulting in an effectively positive charge of a Ti ion in an $\mathrm{Al}$ site.

Conductivity is proportional to carrier concentration and its mobility. Because dopant concentration is very small inside the lattice, we may assume that the mobility of the $\mathrm{Al}$ vacancies is not affected. However, the carrier concentration should be considered in terms of thermodynamic aspects. A Ti ion with the effective positive charge can form an associate with negatively charged $\mathrm{Al}$ vacancy, as in:

$$
\mathrm{Ti}_{\mathrm{Al}}^{\bullet}+V_{A l}^{\prime \prime \prime} \stackrel{\mathrm{AIN}}{\longrightarrow}\left(\mathrm{Ti}_{\mathrm{Al}}^{\bullet}-V_{A l}^{\prime \prime \prime}\right)
$$


The activation energy difference of the grain conductivity with the addition of $\mathrm{TiO}_{2}, 0.37 \mathrm{eV}$, must stem from the binding energy of the association of two ionic defects. Similarly, an association between an electron and a Ti ion is also possible. Ti can be a redox center; however, in this case, the size of the $\mathrm{Ti}^{3+}$ ion after the reduction is too large for it to be accommodated at the $\mathrm{Al}$ site. Therefore, instead of the traditional reduction process, in which the valance changes with the accepting of an electron, electrons appear to be loosely bound to $\mathrm{Ti}^{4+}$ ions with a binding energy.

Activation energies of grain and grain boundary were very similar in each specimen. This can be attributed to the similar structural or electrical environment of grains and grain boundaries. Another possibility is a current-constriction effect coming from lateral inhomogeneity in the specimen or nonideal contact of the electrode. In such cases, the activation energy from a semicircle in the lower frequency range must be the same as that from the bulk. ${ }^{18)}$ However, it is not clear which mechanism is responsible for the identical levels of activation energy; this point will need further investigation.

On the other hand, the very low electron transference number of AlN ceramics regardless of Ti addition means that AlN is predominantly an ionic conductor. This effect appears in the current variation with the time at constant DC voltage, as shown in Fig. 8. Because the measurement temperature is low, the exchange reaction of ions in the electrode must be very limited. So, the silver electrode is believed to effectively block the ion transfer in the electrode. Thus, the initial current at $\mathrm{t}=0$, which is contributed to by both ionic and electronic carriers, is high and decreases abruptly at the beginning and then slowly with time. The steady-state current is obtained as $\mathrm{Al}$ vacancy concentration profiles develop inside the specimen. The kinetics can be determined by a chemical diffusivity of AlN ceramics. The chemical diffusivity $D^{\delta}$ is expressed as ${ }^{19)}$

$$
D^{\delta}=t_{e} D_{i o n}+t_{i o n} D_{e}
$$

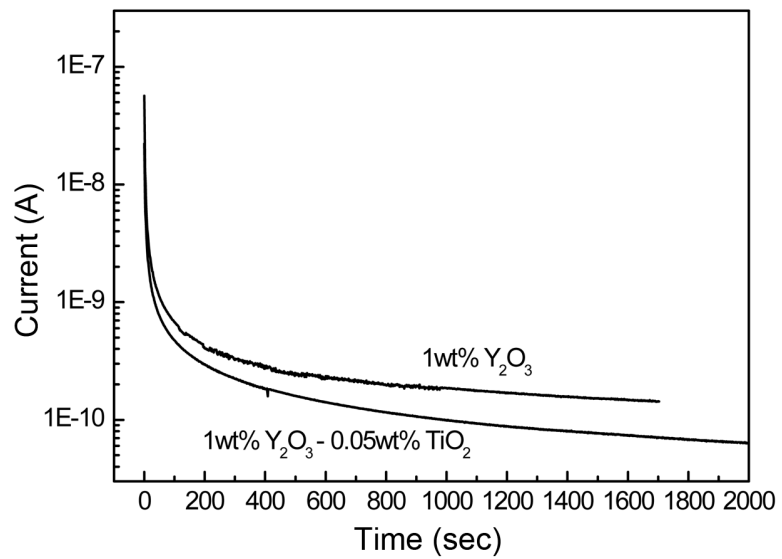

Fig. 8. Current variation with time for the specimens sintered with1 wt\% of $\mathrm{Y}_{2} \mathrm{O}_{3}$ and with additional amount of $\mathrm{TiO}_{2}$ dopant of $0.05 \mathrm{wt} \%$. where $t_{e}, t_{i o n}, D_{e}$, and $D_{i o n}$ are the transference numbers and diffusivities of electrons and ions, respectively. In our case, $t_{i o n}\left(=1-t_{e}\right)$ is nearly one, and thus the chemical diffusivity can be simply expressed as

$$
D^{\delta}=D_{e}
$$

Therefore, from the relaxation time of the exponential current decay at constant voltage, we can obtain the diffusivity of the electrons and the electron concentration can be theoretically calculated using the Nernst-Einstein relation. ${ }^{20)}$ However, this procedure to obtain the electron concentration requires us to be very cautious because electron trapping and grain boundary effects should be considered. ${ }^{21)} \mathrm{A}$ rough calculation shows that the electron concentration is on the order of $10^{12} / \mathrm{m}^{3}$, which is very low compared to the values of typical ceramics.

The facts that the electron transference number $t_{e}$ is close to zero and the electron concentration is also very low compared to that of ionic carriers in AlN ceramics have an important implication in the application of AlN ceramics. For instance, when a voltage is applied in an AlN heater used in a CVD equipment, electric insulation does not occur until a certain incubation time is reached because the initial current established by the ions is significant. Second, even if the voltage is turned off, current can flow in the opposite direction due to a restoration to the equilibrium concentration profile of the $\mathrm{Al}$ vacancies from the profile developed during the voltage application. Both kinetics depend on the chemical diffusivity, which can be approximated by the electron diffusivity in AlN ceramics, for which the ionic transference number is close to one. In an application of an electrostatic chuck, the kinetics can also affect the practical chucking and dechucking times of wafers. If the electron diffusivity is high, then the chucking and dechucking times can be reduced because the current decay, as shown in Fig. 8, can be faster. Also, an AlN substrate in a power device package that operates at high voltage may show effects of current surges when high voltage is applied.

\section{Conclusions}

The electrical properties of AlN ceramics have been analyzed with respect to $\mathrm{TiO}_{2}$ dopant addition. $\mathrm{TiO}_{2}$ addition greatly decreased grain and grain boundary conductivities. With the $\mathrm{TiO}_{2}$ dopant, the activation energy of the grain conductivity increased about $0.37 \mathrm{eV}$; this increase was attributed to the formation of an associate between $\mathrm{Al}$ vacancies and $\mathrm{Ti}$ ions at the $\mathrm{Al}$ site. Similarly, the electronic conductivity was reduced with $\mathrm{TiO}_{2}$ addition, but the extent of reduction was not as great as the extent of reduction of the ionic conductivity. The activation energy for electronic conductivity increased similarly by about $0.37 \mathrm{eV}$. The $\mathrm{TiO}_{2}$ solubility in AlN grains was very low, below the detection limit of typical EDX analysis. Grain boundary was clean, without liquid film, but it showed yttrium segregation. The 
transference number of ions was close to 1 , showing that $\mathrm{AlN}$ ceramics are predominantly ionic conductors. This was confirmed again by considering the current variation at constant voltage. This current variation with time can be understood with respect to the electron diffusivity.

\section{Acknowledgements}

This research was partly supported by a grant from the Fundamental R\&D Program for Core Technology of Materials, funded by the Ministry of Trade, Industry and Energy, Republic of Korea.

\section{REFERENCES}

1. D. R. Wright, L. Chen, P. Federlin, and K. Forbes, "Manufacturing Issues of Electrostatic Chucks," J. Vac. Sci. Tech. $B, 13$ [4] 1910-16 (1995).

2. J. F. Daviet, I. Peccoud, and F. Mondon, "Electrostatic Clamping Applied to Semiconductor Plasma Processing I. Theoretical Modeling," J. Electrochem. Soc., 140 [11] 324556 (1993)

3. T. Watanabe, T. Kitabayashi, and C. Nakayama, "Electrostatic Force and Absorption Current of Alumina Electrostatic Chuck," Jpn. J. Appl. Phys., 31 [7R] 2145 (1992).

4. Y. Imanaka, Y. Suzuki, T. Suzuki, K. Hirao, T. Tsuchiya, H. Nagata, J. S. Cross (eds), Advanced Ceramic Technologies and Products, The Ceramic Society of Japan, 2012.

5. A. V. Virkar, T. B. Jackson, and R. A. Cutler, "Thermodynamic and Kinetic Effects of Oxygen Removal on the Thermal Conductivity of Aluminum Nitride," J. Am. Ceram. Soc., 72 [11] 2031-42 (1989).

6. F. Miyashiro, N. Iwase, A. Tsuge, F. Ueno, M. Nakahashi, and T. Takahashi, "High Thermal Conductivity Aluminum Nitride Ceramic Substrates and Packages," IEEE Trans. Comp., 13 [2] 313-19 (1990).

7. K. Watari, H. J. Hwang, M. Toriyama, and S. Kanzaki, "Effective Sintering aids for low-temperature Sintering of AlN Ceramics," J. Mater. Res., 14 [4] 1409-17 (1999).

8. G.A. Slack, R. A. Tanzilli, R. O. Pohl, J. W. Vandersande, "The Intrinsic Thermal Conductivity of AlN," J. Phys.
Chem. Solids, 48 [7] 641-47 (1987).

9. S. A. Jang and G. M. Choi, "Electrical Conduction in Aluminum Nitride," J. Am. Ceram. Soc., 76 [4] 957-60 (1993).

10. W. J. Lee, S.-M. Lee, K. B. Shim, and H. T. Kim, "Effects of Sintering Conditions on the Electrical Conductivity of 1 wt\% $\mathrm{Y}_{2} \mathrm{O}_{3}$-doped AlN Ceramics," J. Korean Ceram. Soc., 44 [2] 116-23 (2007).

11. H.-S. Kim, J.-M. Chae, Y.-S. Oh, H.-T. Kim, K.-B. Shim, S.M. Lee, "Effects of Carbothermal Reduction on the Thermal and Electrical Conductivities of Aluminum Nitride Ceramics," Ceram. Inter., 36 [7] 2039-45 (2010).

12. M. W. Lee, S.-M. Lee, H. S. Ahn , "High Dense Sintered Body of Aluminum Nitride, Method for Preparing the same and Member for Manufacturing Semiconductor Using the Sintered Body"; Korea Patent 10-0918190 (September 14, 2009).

13. J.-U. Lee, W.-J. Lee, and S.-M. Lee, "The Effects of $\mathrm{TiO}_{2}$ Addition on the Electrical Insulation of AlN Ceramics with $1 \mathrm{wt} \% \mathrm{Y}_{2} \mathrm{O}_{3}$," J. Korean Inst. Electr. Electron. Mater. Eng., in press.

14. ASTM D257-14, "Standard Test Methods for DC Resistance or Conductance of Insulating Materials," ASTM International.

15. S. Azuma, N. Shibata, T. Mizoguchi, S. D. Findlay, K. Nakamura, and Y. Ikuhara, "Atomic Structure, Energetics, and Chemical Bonding of Y-doped $\Sigma 13$ Grain Boundaries in $\alpha-\mathrm{Al}_{2} \mathrm{O}_{3}$, , Philos. Mag., 93 10-2 (2013).

16. I. A. Abrikosov, A, Knutsson, B. Alling, F. Tasnadi, H. Lind, L. Hultman, and M. Odén, "Phase Stability and Elasticity of TiAlN," Materials, 4 [9] 1599-618 (2011).

17. R. D. Shannon, "Revised Effective Ionic Radii and Systematic Studies of Interatomic Distances in Halides and Chalcogenides," Acta Crystallographica Section A: Crystal Physics, Diffraction, Theoretical and General Crystallography, 32 [5] 751-67 (1976).

18. J. Fleig and J. Maier, "The Influence of Current Constriction on the Impedance of Polarizable Electrodes," J. Electrochem. Soc., 144 [11] L302-5 (1997).

19. J. Maier, Physical Chemistry of Ionic Materials; pp. 300-5, John Wiley \& Sons, UK, 2004.

20. ibid., pp444-453.

21. ibid., pp319-332. 